\title{
MICROSTRUCTURAL CHARACTERIZATION OF SUPERALLOY 718 WITH BORON AND PHOSPIIORUS ADDITIONS
}

\author{
J. A. Horton, C. G. McKamey, M. K. Miller* \\ Oak Ridge National Laboratory, Oak Ridge, TN 37831-6115 \\ W. D. Cao and R. L. Kennedy \\ Teledyne Allvac, Monroe, NC 28110-0531
}

\begin{abstract}
Boron and phosphorus additions are known to improve the stress rupture properties of IN718. One possible mechanism to explain this property improvement relies on the boron and phosphorus additions slowing down the growth of $\gamma^{\prime \prime}$ and $\gamma^{\prime}$ precipitates during high temperature service or aging. However, atom probe analysis found no segregation of boron and phosphorus to $\gamma-\gamma^{\prime \prime}$ or to $\gamma-\gamma^{\prime}$ interfaces in the alloys with the high boron and high phosphorous levels. No difference in growth rates were found by transmission electron microscopy in the sizes of the $\gamma^{\prime \prime}$ or $\gamma^{\prime}$ in alloys with high phosphorus and high boron as compared to commercial alloys and to alloys with even lower levels of phosphorus and boron. Atom probe analysis further found that much of the phosphorus, boron, and carbon segregated to grain boundaries. Creep curves comparing the alloys with high levels of phosphorus and boron and alloys with low levels of phosphorus and boron show a large difference in strain rate in the first hours of the test. These results suggest that the boron and phosphorus may have a direct effect on dislocation mobility by some pinning mechanism.
\end{abstract}

\section{INTRODUCTION}

Optimization of the phosphorus, boron and carbon levels in Inconel alloy 718 has been found by Can and Kennedy to significantly improve the stress-rupture properties [1-2]. For example, a commercial grade 718 with $0.03 \mathrm{wt} . \% \mathrm{C}, 0.008 \% \mathrm{P}$, and $0.004 \% \mathrm{~B}$ has a stress rupture life of $200 \mathrm{~h}$ at $690 \mathrm{MPa}$ at $650^{\circ} \mathrm{C}$, while if the phosphorus and boron are increased to $0.022 \% \mathrm{P}$ and $0.011 \% \mathrm{~B}$ with a carbon level of $0.005 \%$, then the stress rupture life increases to $750 \mathrm{~h}$. This study not only found an individual improvement from higher levels of phosphorus or boron, but found an even greater effect when both phosphorus and boron levels were increased.

One possible mechanism to explain this property improvement relies on the boron and phosphorus additions slowing down the growth of $\gamma^{\prime \prime}$ and $\gamma^{\prime}$ precipitates during high temperature service or aging. Growth of $\gamma^{\prime \prime}$ and $\gamma^{\prime}$ precipitates during service has been thoroughly documented by Wlodek and Field [3] for times up to $50,000 \mathrm{~h}$ and temperatures up to $704^{\circ} \mathrm{C}$. In this study, the growth rales of the $\gamma^{\prime \prime}$ and $\gamma^{\prime}$ precipitates with low levels, commercial levels, and high levels of phosphorus and boron were compared by transmission electron microscopy (TEM) on crept and statically annealcd specimens. Creep curves were generated and the segregation behavior of boron, phosphorus, and carbon was investigated by atom probe field ion microscopy (APFIM).

* Research sponsored by the Division of Materials Sciences and by the Laboratory Technolngy Applications Division. Office of Energy Research, U.S. Dept. of Energy, under contract DE-AC05-96OR22464 with Oak Ridge National Laboratory managed by Lockheed Martin Energy Research Corp. This research was conducted utilizing the Shared Research Equipment User Program facilities at Oak Ridge National Laboratory.

\footnotetext{
Superalloys 718, 625, 706 and Various Derivatives Edited by E.A. Loria

The Minerals, Metals \& Materials Society, 1997
} 
Table I Alloy Compositions in wt.\%

\begin{tabular}{ccccc}
\hline & IN-718 & High Purity & Commercial & Microalloyed \\
& Specification & G988 & G457 & G727 \\
\hline $\mathrm{Ni}$ & $50-55$ & balance & balance & balance \\
$\mathrm{Cr}$ & $17-21$ & 17.9 & 17.8 & $17.9(19.9$ at.\%) \\
$\mathrm{Fe}$ & balance & 19.4 & 19.4 & $19.3(20.0$ at.\% $)$ \\
$\mathrm{Nb}+\mathrm{Ta}$ & $4.75-5.5$ & 5.22 & 5.06 & $5.05(3.15$ at.\% $)$ \\
$\mathrm{Mo}$ & $2.8-3.3$ & 2.95 & 2.87 & $2.86(1.73$ at.\%) \\
$\mathrm{Ti}$ & $0.65-1.15$ & 0.92 & 0.92 & $0.92(1.11$ at.\%) \\
$\mathrm{Al}$ & $0.2-0.8$ & 0.47 & 0.63 & $0.58(1.25$ at.\%) \\
$\mathrm{B}$ & $\mathbf{0 . 0 0 6}$ max. & $<\mathbf{0 . 0 0 1}$ & $\mathbf{0 . 0 0 4}$ & $\mathbf{0 . 0 1 1 ( 0 . 0 5 9}$ at.\%) \\
$\mathrm{P}$ & $\mathbf{0 . 0 1 5}$ max. & $<\mathbf{0 . 0 0 1}$ & $\mathbf{0 . 0 0 6}$ & $\mathbf{0 . 0 2 2}(\mathbf{0 . 0 4 1}$ at.\%) \\
$\mathrm{C}$ & 0.08 max. & 0.008 & 0.031 & $0.009(0.043$ at.\%) \\
$\mathrm{Si}$ & 0.35 max. & 0.01 & 0.1 & $0.01(0.02$ at.\%) \\
$\mathrm{N}$ & - & 0.015 & 0.0037 & $0.002(0.08$ at.\%) \\
$\mathrm{S}$ & $\mathbf{0 . 0 1 5 \operatorname { m a x } .}$ & 0.0008 & 0.0004 & $0.0004(0.001$ at.\%) \\
\hline
\end{tabular}

\section{EXPERIMENTAL PROCEDURE}

Table I lists the compositions of the three alloys studied (Teledyne Allvac alloy numbers G988, G457, and G727) as measured by Teledyne. Wrought bars were obtained from Teledyne with a solution heat treatment at $954^{\circ} \mathrm{C}$ for $1 \mathrm{~h}$ followed by an air cool and aging at $718^{\circ} \mathrm{C}$ for $8 \mathrm{~h}$, furnace cooling at $55^{\circ} \mathrm{C} / \mathrm{h}$ to $621^{\circ} \mathrm{C}$, followed by an air cool. Static anneals were subsequently carried out at ORNL on slices encapsulated in evacuated quartz capsules at a temperature of $704^{\circ} \mathrm{C}$ for periods up to 6 months. Creep tests were conducted in air on $3 \mathrm{~mm}$ dia. specimens with an $18 \mathrm{~mm}$ gage length at temperatures of 649 or $704^{\circ} \mathrm{C}$ and various loads, as listed in Table II. TEM was performed on both crept and statically annealed specimens at $300 \mathrm{kV}$. Dark field images along 100 poles around the inner ring of superlattice reflections with indices of $010,011 / 2,011,01 / 21,001$, etc. were made using the 10 channel dark field capability. This allowed for all three variants of the $\gamma^{\prime \prime}$ from one area to be imaged. Exposure times were typically $45 \mathrm{~s}$ to $1 \mathrm{~min}$. with $10 \mathrm{~min}$. in the D19 developer. Measurements of the precipitate size and area fraction were made with Buehler's Omnimet image analysis system. Atom probe analysis was performed with the ORNL energy-compensated atom probe at a specimen temperature of $50 \mathrm{~K}$ and a pulse fraction of $20 \%$. Field ion micrographs were made at a specimen temperature of 50-60 K with neon as the imaging gas. Further details on the atom probe analyses were previously published [4].

Table II Creep Conditions

\begin{tabular}{cccccc}
\hline Alloy & $\begin{array}{c}\text { Creep Temp, } \\
{ }^{\circ} \mathrm{C}\end{array}$ & $\begin{array}{c}\text { Load, MPa } \\
(\mathrm{ksi})\end{array}$ & $\begin{array}{c}\text { Rupture } \\
\text { Time, hr }\end{array}$ & $\begin{array}{c}\text { Elongation } \\
\text { at Failure }\end{array}$ & $\begin{array}{c}\text { Min. Creep } \\
\text { Rate, \%/s }\end{array}$ \\
\hline G457 & 649 & $620(90)$ & 108 & $26.3 \%$ & $1.9 \times 10^{-6}$ \\
G727 & 649 & $690(100)$ & 1436 & $7.4 \%$ & $2.4 \times 10^{-7}$ \\
G727 & 704 & $379(55)$ & $>>32$ & $\begin{array}{c}\text { stopped at } \\
0.6 \%\end{array}$ & $1.9 \times 10^{-6}$ \\
G988 & 704 & $379(55)$ & 37 & $8.85 \%$ & $1.9 \times 10^{-5}$ \\
\hline
\end{tabular}



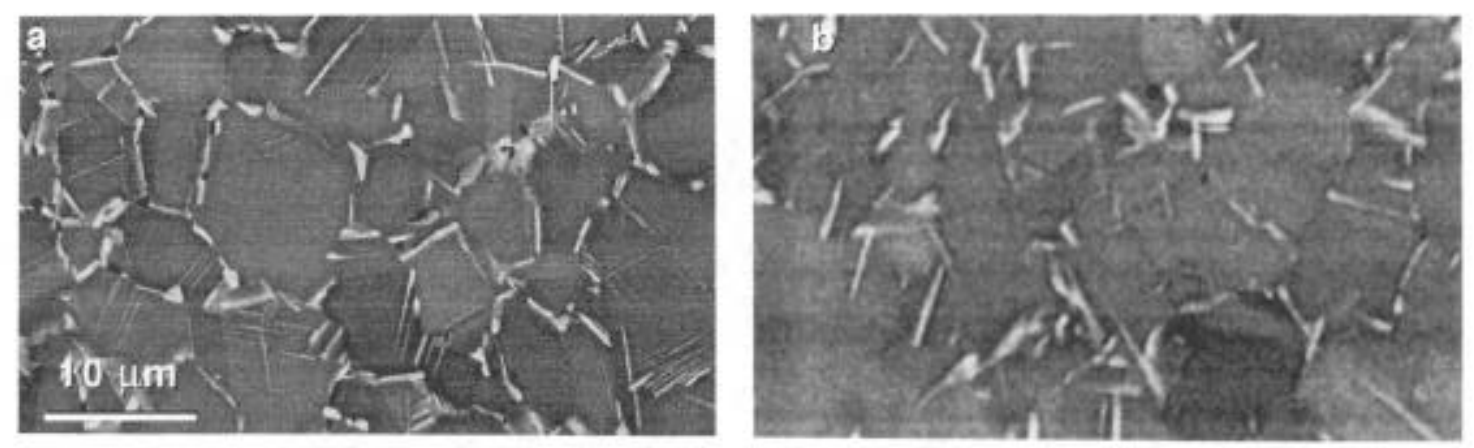

Fig. I. Backscanered electron images of as-polished (no etching) of (a) G727 and (b) G988.

\section{RESULTS AND DISCUSSION}

No obvious differences were found by optical microscopy between the high purity and microalloyed alloys in the phase distribution of the larger precipitates present in alloy 718 both before and after heat treatments or creep experiments [1-2]. Analyses of these phases have been extensively described [3,5] and so was not investigated here. The emphasis in the current study concerned the stability of the much finer distribution of $\gamma^{\prime \prime}$ and $\gamma^{\prime}$ precipitates and the segregation pattern of the phosphorus and the boron. Figure 1 shows scanning electron microscope images using backscattered electrons of as-polished, i.e. with no chemical etching, of specimens showing the starting microstructures. Again no differences in the precipitation was apparent. Grain size was ASTM 11.

\section{Transmission Electron Microscopy}

Mean sizes of $\gamma^{\prime \prime}$ precipitates and typical diameters of the smaller $\gamma^{\prime}$ are given in Table III. Figures $2 \mathrm{a}, 2 \mathrm{~b}, 3 \mathrm{a}$, and $3 \mathrm{~b}$ show the $\gamma^{\prime \prime}$ precipitates on edge. $\gamma^{\prime \prime}$ precipitates listed in Table III as variant 1 were in the plan view orientation, i.e. the disks were flat. Note in Fig $2 \mathrm{c}$ and $3 \mathrm{c}$ that these disks are not all that round, especially in Fig. $3 \mathrm{c}$ where after the longest anneal, the $\gamma^{\prime \prime}$ precipitates are rather rectangular shaped. $\gamma^{\prime}$ precipitates are visible in (a) and (c) as the smaller circular precipitates. Areas were chosen for analysis that were away from the denuded zones near some grain boundaries. The same precipitate measuring technique was applied to all the specimens. Although hundreds of precipitates were measured, there are a

Table III Sizes of $\gamma^{\prime}$ and $\gamma^{\prime \prime}$

\begin{tabular}{|c|c|c|c|c|c|c|c|}
\hline \multirow[b]{2}{*}{ Alloy } & \multirow{2}{*}{$\frac{\gamma^{\prime}}{\substack{\text { typical da. } \\
\text { nm }}}$} & \multicolumn{2}{|c|}{$\gamma^{\prime \prime}$ variant 1} & \multicolumn{2}{|c|}{$\gamma^{\prime \prime}$ variant 2} & \multicolumn{2}{|c|}{$\gamma^{\prime \prime}$ variant 3} \\
\hline & & $\begin{array}{c}\text { area } \\
\text { fraction, } \\
\xi\end{array}$ & $\begin{array}{c}\text { mean } \\
\text { breadth } \times \\
\text { length, nm }\end{array}$ & $\begin{array}{c}\text { area } \\
\text { fraction. } \\
\%\end{array}$ & $\begin{array}{c}\text { mean } \\
\text { breadth } \times \\
\text { length, } \mathrm{nm}\end{array}$ & $\begin{array}{c}\text { area } \\
\text { fraction. } \\
\%\end{array}$ & $\begin{array}{l}\text { mean } \\
\text { breadth } \times \\
\text { length, nm }\end{array}$ \\
\hline \multicolumn{8}{|c|}{ Creptat $649^{\circ} \mathrm{C}$} \\
\hline G457 & obscured & 9 & $9 \times 21$ & 11 & $10 \times 26$ & 9 & $7 \times 24$ \\
\hline G327 & & 17 & $10 \times 28$ & 6 & $8 \times 30$ & 8 & $8 \times 28$ \\
\hline \multicolumn{8}{|c|}{ Crepe at $704^{\circ} \mathrm{C}$} \\
\hline G727 & $10-20$ & 14 & $10 \times 36$ & 4 & $7 \times 34$ & & \\
\hline G988 & $10-20$ & 19 & $12 \times 49$ & 2 & $8 \times 32$ & & \\
\hline \multicolumn{8}{|c|}{ Static Anneal. 406 hrs at $704 \mathrm{C}$} \\
\hline G727 & $25-35$ & 6 & $50 \times 90$ & 5 & $9 \times 54$ & & \\
\hline C988 & $25-35$ & 6 & $50 \times 100$ & 6 & $12 \times 72$ & & \\
\hline \multicolumn{8}{|c|}{ Shatic Anneal. 6 menthr at $704^{\circ} \mathrm{C}$} \\
\hline G457 & $40-60$ & 6 & $100 \times 300$ & 1 & $20 \times 160$ & 1 & $30 \times 240$ \\
\hline G727 & $40-60$ & 14 & $150 \times 320$ & 4 & $17 \times 130$ & 2 & $14 \times 130$ \\
\hline G988 & $40-60$ & 7 & $85 \times 260$ & 3 & $22 \times 140$ & 2 & $20 \times 150$ \\
\hline
\end{tabular}


number of experimental variables which adversely affect the accuracy of the results. These include inhomogeneities in the specimens, slight differences in diffracting conditions, and slight differences in photographic exposure conditions. The final conclusion reached here was that, in comparing the alloys with different phosphorus and boron levels, there was no significant difference in precipitate sizes in either $\gamma^{\prime \prime}$ or $\gamma^{\prime}$ precipitates after creep or after the static anneals used here.
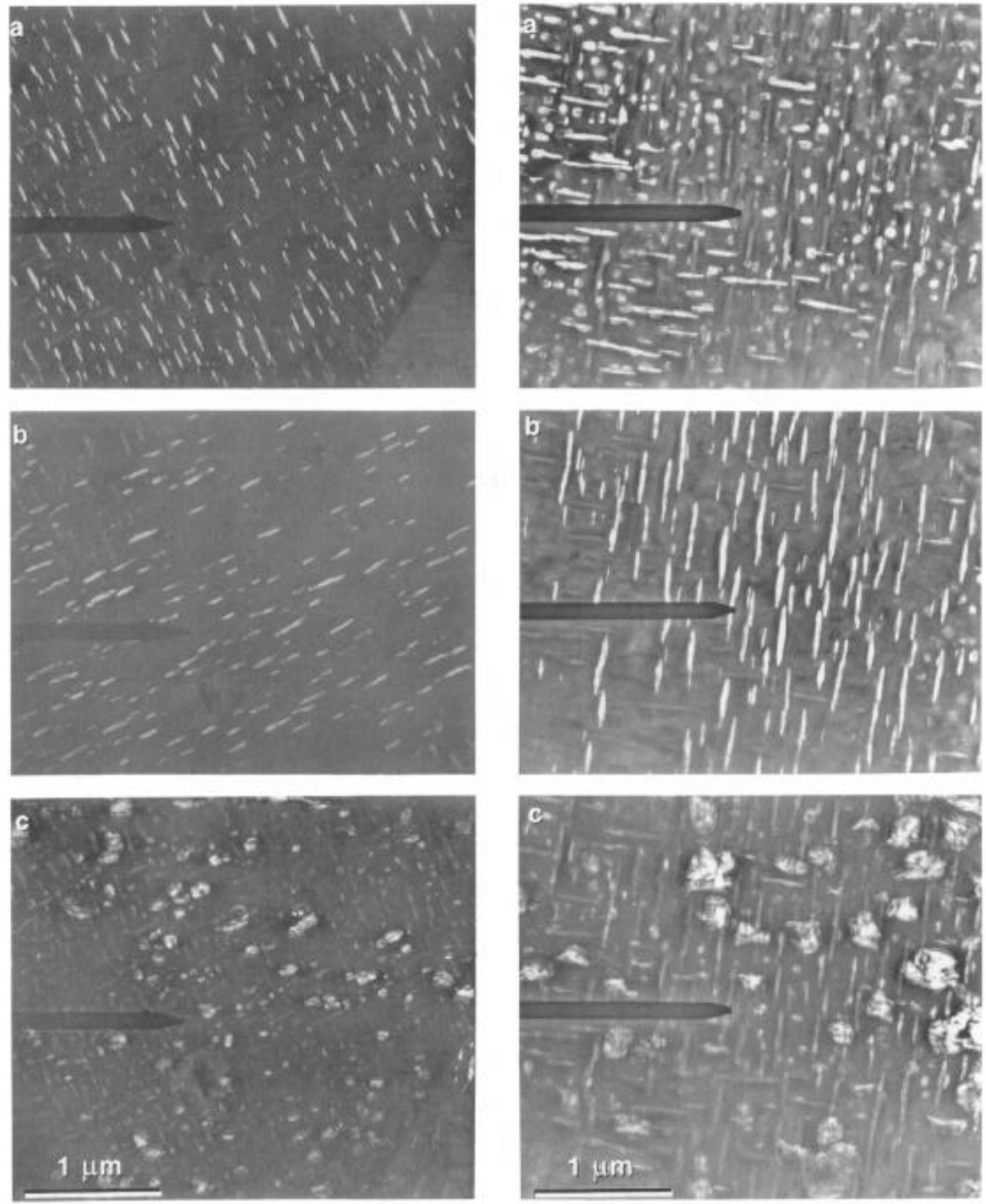

Fig. 2 Alloy $G 727$ after 406 hrs at $704^{\circ} \mathrm{C}$ showing the three variants of $\gamma^{\prime \prime} . \gamma^{\prime}$ precipitates are more visible in (a) and (c) as the smaller circular precipitates. Both Fig. 2 and 3 were made at a 11001 zone axis using ( $a$ )- 001 (b)- $01 / 21$ (c)-011 reflections.

Fig. 3 Alloy $G 727$ after 6 mon. at $704^{\circ} \mathrm{C}$. $\gamma^{\prime \prime}$ are disk-shaped precipitates viewed on edge in (a) and (b) and viewed flat in (c). The exact same area is shown in $a, b$, and $c$ in both Figs. 2 and 3. 
Table IV Compositions as Measured by Atom Probe

\begin{tabular}{|c|c|c|c|c|c|c|}
\hline & \multicolumn{3}{|c|}{ G988 High Purity Alloy (at.\%) } & \multicolumn{3}{|c|}{ G727 Microalloyed (at.\%) } \\
\hline & $\gamma$ & $\gamma^{\prime}$ & $\gamma^{\prime \prime}$ & $\gamma$ & $\gamma^{\prime}$ & $\gamma^{\prime \prime}$ \\
\hline $\mathrm{Cr}$ & 21.7 & 0.3 & 1.1 & 21.4 & 0.7 & 1.3 \\
\hline $\mathrm{Fe}$ & 23.7 & 2.1 & 1.6 & 24.0 & 1.9 & 1.2 \\
\hline $\mathrm{Nb}$ & 0.9 & 8.9 & 20.9 & 1.1 & 6.4 & 19.8 \\
\hline Mo & 2.3 & 0.2 & 1.5 & 1.8 & 0.08 & 0.7 \\
\hline $\mathrm{Ti}$ & 0.3 & 10.0 & 4.7 & 0.4 & 9.6 & 5.2 \\
\hline Al & 0.8 & 9.0 & 0.15 & 0.4 & 8.8 & 0.4 \\
\hline B & - & - & - & 0.02 & - & - \\
\hline$P$ & - & - & - & - & - & - \\
\hline $\mathrm{N} / \mathrm{Si}$ & 0.07 & - & - & 0.05 & - & - \\
\hline
\end{tabular}

\section{Atom Probe-Field Ion Microscopy}

No solute enrichments, including boron and phosphorus, were observed by field ion microscopy at either the $\gamma^{\prime \prime}$ or $\gamma^{\prime}$ precipitate/matrix interfaces in either the microalloyed or the high purity alloy. No evidence of solute enrichments were obtained from atom probe composition profiles across the $\gamma^{\prime \prime}$ or $\gamma^{\prime}$ precipitate/matrix interfaces. The compositions of the $\gamma$ matrix and the $\gamma^{\prime \prime}$ and $\gamma^{\prime}$ precipitates are given in Table IV. Further details can be found in ref. 14]. In the microalloyed specimen, note the depletion of phosphorus to below the detectability limits in all three phases and the depletion of boron to $1 / 3$ the nominal value in the matrix and to less than the detection limits in the $\gamma^{\prime \prime}$ or $\gamma^{\prime}$ phases. The amount of phosphorus added to the alloy was 0.04 at.\%. The critical amount needed for a beneficial effect is 0.02 at.\%. The detection limit for the atom probe mcasurements in the matrix was 0.01 at. \%. The amount measured in the matrix was below this level. Based on these compositions, a summary of the partitioning behavior is presented in Table V.

Table V Partitioning Behavior Based on Atom Probe Compositions

\begin{tabular}{cccc}
\hline $\begin{array}{c}\text { Alloying } \\
\text { Element }\end{array}$ & $\begin{array}{c}\text { Had highest } \\
\text { concentration in }\end{array}$ & $\begin{array}{c}\text { Had the 2nd highest } \\
\text { level in }\end{array}$ & $\begin{array}{c}\text { Had the 3rd highest } \\
\text { level in }\end{array}$ \\
\hline $\mathrm{Nb}$ & Phosphide & $\gamma^{\prime \prime}$ & $\gamma^{\prime}$ \\
$\mathrm{Mo}$ & Phosphide & $\gamma$ & GB \\
$\mathrm{Ti}$ & $\gamma^{\prime}$ & $\gamma^{\prime \prime}$ & Phosphide \\
$\mathrm{Al}$ & $\gamma^{\prime}$ & & \\
$\mathrm{B}$ & $\mathrm{GB}$ & Phosphide & \\
$\mathrm{P}$ & $\mathrm{GB}$ & Phosphide & \\
$\mathrm{Ni}$ & $\gamma^{\prime \prime}$ & $\gamma^{\prime}$ & \\
$\mathrm{Cr}$ & $\gamma$ & & \\
$\mathrm{Fe}$ & $\gamma$ & & \\
\hline
\end{tabular}


Table VI Solute Grain Boundary Coverage in Alloy G727

\begin{tabular}{cc}
\hline Solute & Monolayer Coverage \\
\hline Boron & $61 \%$ \\
Phosphorus & $37 \%$ \\
Carbon & $5.7 \%$ \\
Nitrogen/Silicon & $1.9 \%$ \\
\hline
\end{tabular}

In the microalloyed specimens, a significant segregation of boron and phosphorus to grain boundaries was found. In the atom probe, a cylindrical core of material is sampled along a grain boundary. In effect, as the evaporation proceeds, the grain boundary traverses the probe hole. A statistical technique was used to determine the level at the boundary (assuming an effective grain boundary thickness of $0.2 \mathrm{~nm}$ width) even though the probe hole is slightly wider. The monolayer calculation then assumes a normal metallic atomic spacing, so that a coverage of $61 \%$ would mean that there was $61 \%$ as many boron atoms as metal atoms in a volume $0.2 \mathrm{~nm}$ thick, see Table VI. No indication could be made on whether the boron is present interstitially or not. A typical field ion micrograph of alloy G727 is shown in Fig. 4. This particular image shows brightly imaging spots on a grain boundary and also includes a phosphide particle near the grain boundary.

The observation of boron and carbon segregation to grain boundaries is consistent with several previous atom probe investigations in nickel-based superalloys. Buchon et al. [6] reported high boron levels and occasionally carbon enrichment at decorated (with brightly imaging spots) $\gamma-\gamma$ boundaries in an NA4 nickel-based superalloy containing 0.11 at. $\% \mathrm{~B}$ and $0.14 \% \mathrm{C}$. Boron and carbon segregation was found by Stiller [7] in Alloy 600 with 0.005 at.\% B and 0.18 at.\% C and in Alloy 690 with 0.005 at. \% B and 0.09 at. \% C. Letellier et al. [8] found a $2 \mathrm{~nm}$ thick boron and molybdenum enriched zone along $\gamma / \gamma, \gamma / \gamma^{\prime}$, $\gamma^{\prime} / \gamma^{\prime}$ interfaces in an Astroloy containing 0.11 at.\% B.

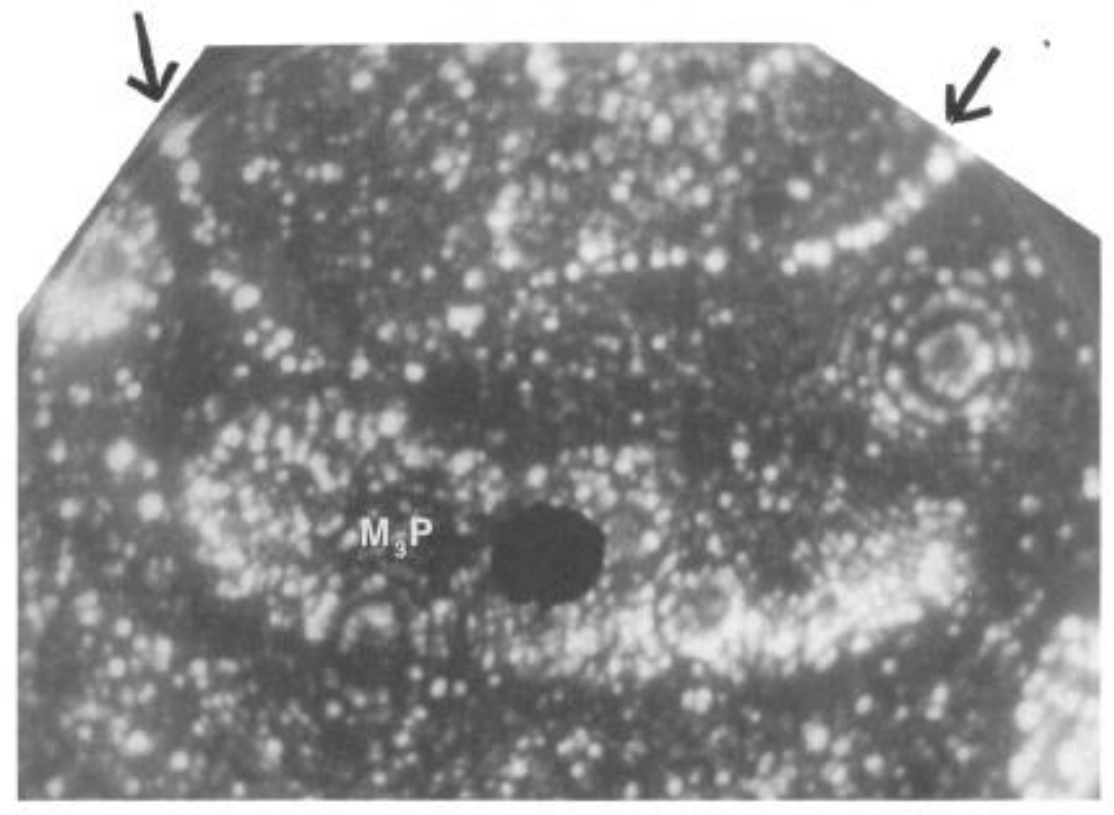

Fig. 4 Field ion micrograph of a grain boundary in alloy G727 showing bright spot decoration along a grain boundary (arrowed) and a neighboring oval-shaped phosphide precipitate. 


\section{Creep Tests}

Typical creep curves for the alloys used in this study are shown in Fig. 5. Analyses of the fracture modes indicated no differences in the fracture morphology between the three alloys; rupture occurred in a ductile manner. The microalloyed G727 alloy clearly shows superior creep strength as compared to the other two alloys. Comparison of the curves for the three alloys suggests that whatever strengthening mechanism is operative in the G727 alloy is present at the beginning of the creep test and is not the result of any extensive aging during the test. For example, after $10 \mathrm{~h}$ of creep testing at $704^{\circ} \mathrm{C}$, a period of time far too low for any aging or growth of phases to have occurred, the high-purity G988 alloy has already entered tertiary creep and is almost to failure, while the G727 alloy has only just reached the minimum creep rate regime. TEM examinations showed no significant differences in precipitate sizes after creep tests, Table III.
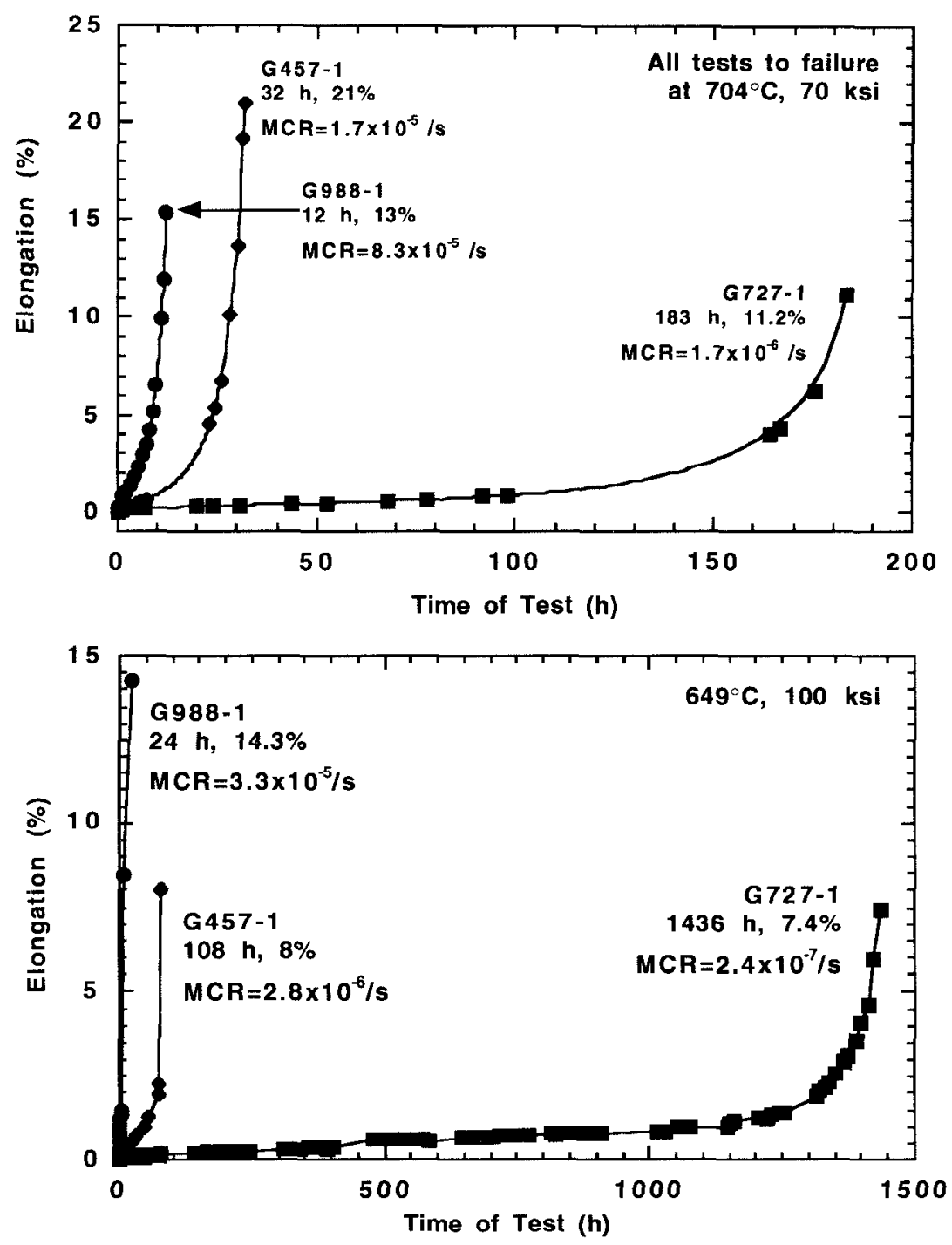

Fig. 5. Creep curves for the commercial alloy $G 457$, the high purity (low levels of $P \& B$ ) G988 alloy, and microalloyed (high levels of $P \& B$ ) G727. Tests were performed in air. 


\section{SUMMARY AND CONCLUSIONS}

Phosphorus and boron additions improve the stress rupture life and creep rates of Inconel 718 . Since the principal strengthening mechanism in Alloy 718 is the presence of $\gamma^{\prime \prime}$ and $\gamma^{\prime}$ precipitates, it was first suspected that the improvement in creep properties in alloy G727 microalloyed with phosphorus and boron was a result of boron and phosphorus pinning the precipitates and slowing their growth. However, no segregation of phosphorus and boron was found by atom probe at $\gamma^{\prime \prime}$ and $\gamma^{\prime}$ interfaces and no difference in $\gamma^{\prime \prime}$ or $\gamma^{\prime}$ precipitate stability was observed by TEM after creep tests or after long term static anneals at $704^{\circ} \mathrm{C}$. The phosphorus and boron were found strongly segregated to $\gamma-\gamma$ grain boundaries. The creep curves show that differences in the creep strength of the alloys are apparent at the beginning of the tests and do not require long aging times. Aside from grain boundary effects, this suggests as another possibility, that the beneficial effects of phosphorus and boron result from a dislocation pinning mechanism.

\section{ACKNOWLEDGEMENTS}

The authors wish to thank C.T. Liu and M. G. Burke for useful discussions and K. F. Russell, J. W. Jones, J. L. Wright, and C. A. Carmichael for technical assistance.

\section{REFERENCES}

1. W. Cao and R. L. Kennedy, "The Effect of Phosphorous on Mechanical Properties of Alloy 718" Superalloys 718, 625, 706 and Various Derivatives, Loria, E. A. ed., (The Minerals, Metals \& Materials Sociely, 1994) 463-477.

2. R. L. Kennedy, W. Cao, and W. M. Thomas, "Stress Rupture Strength of Alloy 718", Advanced Materials and Processes, 149, \#3 (1996) 33-35.

3. S. T. Wlodek and R. D. Field, "The Effects of Long Time Exposure on Alloy 718", Superalloys 718, 625, 706 and Various Derivatives, Loria, E. A. ed., (The Minerals, Metals \& Materials Society, 1994) 659-670.

4. M. K. Miller, J. A. Horton, W. D. Cao, and R. L. Kennedy, "Characterization of the Effects of Boron and Phosphorus Additions to the Nickel Based Surperalloy 718", J. de Physique IV, C5, 6 (1996) 241246.

5. M. G. Burke and M. K. Miller, "Precipitation in Alloy 718: ACombined AEM and APFIM Investigation", Superalloys 718, 625, 706 and Various Derivatives, Loria, E. A. ed., (The Minerals, Metals \& Materials Society, 1991) 337-350.

6. A. Buchon, A. Medand and D. Blavette, "Phase Composition and Grain-Boundary Segregation in a Nickel Base Superalloy: a Preliminary TEM-APFIM Investigation", Surf. Sci., 246 (1991) 218-224.

7. K. Stiller, "Investigations of Grain Boundary Microchemistry in Nickel Base Superalloys", Surf. Sci., 246 (1991) 225-230.

8. L. Letellier, A. Bostel, and D. Blavetter, "Direct Observation of Boron Segregation at Grain Boundaries in Astroloy by 3D Atomic Tomography", Scripta Metall., 30 (1994) 1503-1508. 